\title{
Phototransformation kinetics of cyanobacterial toxins and secondary metabolites in surface waters
}

\author{
Regiane Natumi ${ }^{1}$, Sandro Marcotullio ${ }^{2}$ and Elisabeth M.-L. Janssen ${ }^{1 *}$ (i)
}

\begin{abstract}
Background: Cyanobacteria and their toxins occur in high concentrations during the so-called bloom events in surface waters. To be able to assess the risks associated with cyanobacterial blooms, we need to understand the persistence and fate processes of these toxins and other bioactive metabolites. In this study, we investigated the photochemical fate of 54 cyanopeptides extracted from two strains of Microcystis aeruginosa (PCC7806 and UV006), Planktothrix rubescens, and Dolichospermum flos aquae. We determined half-lives during sunlight exposure in lake water and inspected the effect of pH on transformation kinetics for 27 microcystins, 8 anabaenopeptins, 14 cyanopeptolins, 2 cyclamides, and 3 aeruginosins.

Results: For cyanopeptides from D. flos aquae and P. rubescens, we observed the highest removal of 28 and 26\%, respectively, after 3-h sunlight exposure. Most cyanopeptides produced by the two M. aeruginosa strains were rather persistent with only up to $3 \%$ removal. The more reactive cyanopeptides contained amino acids known to undergo phototransformation, including methionine and tyrosine moieties or their derivatives. Photochemical half-lives of 14 tyrosine-containing cyanopeptides decreased by one order of magnitude from nearly persistent conditions at $\mathrm{pH} 7$ (half-life $>70 \mathrm{~h}$ ) to shorter half-lives at $\mathrm{pH} 10(<10 \mathrm{~h})$.

Conclusions: More work is needed to distinguish the contribution of different photochemical reaction pathways including the contributions to the pH effect. To the best of our knowledge, this is the first assessment of transformation kinetics of such a wide range of cyanopeptides. The abundant and persistent cyanopeptides that have not been studied in detail yet should be prioritized for the evaluation of their ecosystem and human health risks and for their abatement during drinking water treatment.
\end{abstract}

Keywords: Cyanopeptide, Cyanobacteria, Microcystin, Phototransformation, Anabaenopeptin, Natural toxins, Surface water, Water quality, Degradation

\section{Background}

Under favorable environmental conditions, such as elevated nutrient concentrations and warm temperatures, cyanobacteria can proliferate to so-called bloom events [1-3]. There is a scientific consensus that cyanobacterial blooms are intensifying globally due to continued

\footnotetext{
*Correspondence: elisabeth.janssen@eawag.ch

${ }^{1}$ Department of Environmental Chemistry, Swiss Federal Institute

of Aquatic Science and Technology (Eawag), 8600 Dübendorf, Switzerland

Full list of author information is available at the end of the article
}

anthropogenic nutrient inputs and the effects of climate change on thermal and hydrological conditions $[1,4,5]$. Cyanobacteria blooms are also called "harmful" because they result in poor water quality and cyanobacteria are able to produce toxic metabolites including microcystins, cylindrospermopsins, anatoxins, and saxitoxins [6-12]. Over the past decades, a legion of additional bioactive secondary metabolites has been identified in laboratory cultures and biomass collected from cyanobacterial bloom events [13-17]. These compounds occupy a wide chemical space from 100 to $2500 \mathrm{Da}$ with $65 \%$ being

\section{Springer Open}

(c) The Author(s) 2021. This article is licensed under a Creative Commons Attribution 4.0 International License, which permits use, sharing, adaptation, distribution and reproduction in any medium or format, as long as you give appropriate credit to the original author(s) and the source, provide a link to the Creative Commons licence, and indicate if changes were made. The images or other third party material in this article are included in the article's Creative Commons licence, unless indicated otherwise in a credit line to the material. If material is not included in the article's Creative Commons licence and your intended use is not permitted by statutory regulation or exceeds the permitted use, you will need to obtain permission directly from the copyright holder. To view a copy of this licence, visit http://creativeco mmons.org/licenses/by/4.0/. 
peptide-based metabolites, called cyanopeptides [18]. Cyanopeptides can be classified by structural similarities including microcystins, aeruginosins, anabaenopeptins, cyanopeptolins, and microginins. One major limitation for their identification is the absence of commercially available reference standards for most cyanopeptides. Consequently, the identification and absolute quantification of most cyanopeptides remain challenging. Few studies quantified absolute concentrations of cyanopeptides beyond the hepatotoxic class of microcystins in lake samples using commercially available bioreagents with slightly lower purity than reference materials or produced their own gravimetric reference materials $[16,19$, 20]. These studies detected other cyanopeptides at similar concentrations and frequency as microcystins $\left(\mu \mathrm{g} \mathrm{L}{ }^{-1}\right.$ range). Furthermore, a recent study demonstrated that the total load of cyanopeptolins and anabaenopeptins can be comparable to microcystins even at the intake of drinking water treatment plants and the concentrations correlated with abundance of cyanobacteria (cell count, chlorophyll-a) [21]. In addition to the release of toxins due to cell lysis, observable concentrations depend on the persistence of each cyanobacterial metabolite in surface water. While most research in the past decades focused on exploring new cyanobacterial metabolites, studies of environmental processes remain mostly elusive with the exception of few microcystins.

Microcystin LR can persist in surface water for several days or weeks [22-25]. Microbial degradation rates of microcystins can vary significantly across microbial species and can depend on their history of exposure to cyanobacterial blooms $[24,26,27]$. Although biodegradation has been reported to be a likely degradation pathway for microcystins, in general, there is a lag period of hours to weeks, which can be caused either by the initially low abundance of bacteria that are able to degrade microcystins or by a change in metabolic activity [22, 27]. In addition to biotic processes, sunlight-driven transformation of cyanopeptides can contribute to their fate in surface waters. Depending on the light penetration and on the naturally occurring photosensitizers, the reported photochemical half-life of microcystin LR ranges from days to months [28-31]. Organic matter in surface waters can act as photosensitizers when they absorb sunlight to form a triplet excited state molecule and subsequently produce other reactive species [32]. In the presence of pigments or dissolved organic matter, photosensitized reactions appear to play an important role in the environmental transformation of microcystins, including reactions with hydroxyl radicals and triplet state excited molecules [33-35]. Thus far, studies mostly focused on the fate of four microcystin variants (MC-LR, MC-RR, MC-YR, MC-LA), while 279 microcystins are known to date [36].
Even less is known about the fate of other cyanopeptides beyond microcystins.

To assess the health risks associated with bloom contaminated waters, more knowledge about the persistence of cyanopeptides in aquatic systems is essential. In this study, we investigated the photochemical fate of the main cyanopeptides produced by two strains of Microcystis aeruginosa as well as Planktothrix rubescens, and Dolichospermum flos aquae. We evaluated the removal during sunlight exposure in lake water and the effects of $\mathrm{pH}$ on transformation kinetics for microcystins, anabaenopeptins, cyanopeptolins, cyclamides, and aeruginosins. Our data indicate that some cyanopeptides are photochemically persistent and other compounds undergo phototransformation by direct or indirect photochemical reactions.

\section{Experimental Section \\ Materials}

Microcystin reference standards for MC-LR, MC-YR, MC-RR, MC-LF, MC-LA, MC-LW, MC-LY, and nodularin (all $>95 \%$ purity by HPLC) were obtained from Enzo Life Science (Lausen, Switzerland) and [D-Asp ${ }^{3}, \mathrm{E}^{\left.-\mathrm{Dhb}^{7}\right]}$ MC-RR (>95\% purity by HPLC) from CyanoBiotech $\mathrm{GmbH}$ (Berlin, Germany). Bioreagents for aeruginosin 98B, cyanopeptolin A, cyanopeptolin D, anabaenopeptin A, anabaenopeptin B, anabaenopeptin NZ857, and oscillamide $\mathrm{Y}$ (all $>90 \%$ purity by HPLC) were obtained from CyanoBiotech GmbH (Berlin, Germany). Aerucyclamide A was obtained as purified bioreagent in dimethyl sulfoxide by Prof. Karl Gademann (University of Zurich, Switzerland) [37]. Additional materials are listed in the Supporting Information (Additional file 1: Text S1).

\section{Cyanobacterial cultures}

Microcystis aeruginosa PCC7806 was originally isolated from Braakman reservoir in The Netherlands (1972) and was obtained from the Pasteur Culture Collection of Cyanobacteria (France). Dolichospermum flos aquae NIVA-CYA 269/6 was originally isolated from Lake Frøylandsvatnet in Norway (1990) and Planktothrix rubescens K-0576 was originally isolated from Lake Borre Sø in Denmark. Both strains were obtained from the Norwegian Culture Collection of Algae (NORCCA). Microcystis aeruginosa UV006 was originally isolated from Hartebeespoort Dam in South Africa and an inoculum was provided by Prof. Jakob Pernthaler (University of Zurich, Switzerland). Primary cultures were kept in $75-\mathrm{mL}$ modified WC medium (Additional file 1: Table S1) at $20 \pm 2{ }^{\circ} \mathrm{C}$ and irradiated at $12 \mu \mathrm{mol}$ photons $\mathrm{m}^{-2} \mathrm{~s}^{-1}$ on a $12: 12-\mathrm{h}$ light/dark cycle [38]. To produce significant amount of biomass, $4.5 \mathrm{~L}$ of sterile WC medium was inoculated with $10-15 \%$ inoculum every four weeks. The 5 -L Schott 
bottles were cultivated at the same conditions described above and aerated with filtered air (GE Healthcare, Whatman, HEPA-VENT, $0.3 \mu \mathrm{m}$ ). All materials used for culturing were autoclaved before use and all the subculturing was performed under sterile conditions.

\section{Cyanopeptide extraction for photochemical experiments}

The cells were harvested by centrifugation ( $\mathrm{rcf}$ of $4000 \mathrm{~g}$ at $10{ }^{\circ} \mathrm{C}, 10 \mathrm{~min}$, Herolab HiCen XL), lyophilized ( $-40{ }^{\circ} \mathrm{C},-3$ mbar, $24 \mathrm{~h}$, Lyovac GT2, Leybold) and stored at $-20{ }^{\circ} \mathrm{C}$ until further analysis. For the extraction, the weight of the dry material was recorded and $\mathrm{MeOH} / \mathrm{H}_{2} \mathrm{O}(70 / 30 \% \mathrm{v} / \mathrm{v})$ was added at a ratio of 200 $\mu \mathrm{L} \mathrm{mg}$ dry,wt $^{-1}$. The suspension was homogenized by vortexing, incubated under sonication (VWR, Ultrasonic cleaner USC-THD, level $6,10 \mathrm{~min}$ at $15^{\circ} \mathrm{C}$ ) and pellets were separated from supernatant by centrifugation ( $\mathrm{rcf}$ of $4660 \mathrm{~g}$ at $10{ }^{\circ} \mathrm{C}, 10 \mathrm{~min}$, Megafuge $1.0 \mathrm{R}$ ). The supernatant was transferred to a new glass vial, the extraction was repeated twice and supernatants were combined. The solvent was evaporated from the pooled extract under a gently stream of nitrogen $\left(40{ }^{\circ} \mathrm{C}\right.$, TurboVap ${ }^{\circledR} \mathrm{LV}$, Biotage) to reduce the methanol content to less than $5 \%$. The extracts were then purified by liquid-liquid extraction (LLE). Therefore, extracts were diluted to a total volume of $25 \mathrm{~mL}$ with nanopure water in a separatory funnel containing $25 \mathrm{~mL}$ of hexane. The funnels were shaken vigorously for 3 min before allowing separation of the two phases again. The water phase was then collected and the hexane phase was discarded. The water phase was extracted with hexane two more times. The extraction allowed to remove a large portion of chromophoric matter with $>90 \%$ reduced absorbance at 665 and $613 \mathrm{~nm}$ indicative of dominating pigments (chlorophylla and phycocyanin, respectively) that would otherwise interfere with the photochemical tests (absorbance spectra of extracts in Additional file 1: Figure S1). The water fraction was concentrated to $300 \mu \mathrm{L}$ by vacuum-assisted evaporation (Syncore ${ }^{\circledR}$ Analyst R-12, BÜCHI Labortechnik $\mathrm{AG}, 40{ }^{\circ} \mathrm{C}, 120 \mathrm{rpm}, 20 \mathrm{mbar}$ ). Each volume was adjusted gravimetrically to $1.0 \mathrm{~mL}$ in nanopure water and stored in the fridge at $4{ }^{\circ} \mathrm{C}$ if used within $24 \mathrm{~h}$ or in the freezer at $-20^{\circ} \mathrm{C}$ until its further use for photochemical experiments.

\section{Cyanopeptide profile in four strains}

To analyze the cyanopeptide profiles from different strains, the biomass was extracted as described above with the difference that $\mathrm{MeOH} / \mathrm{H}_{2} \mathrm{O}(70 / 30 \% \mathrm{v} / \mathrm{v})$ was added at a ratio of $15 \mu \mathrm{L} \mathrm{mg}$ dry,wt $^{-1}$. The extracts were then individually purified by solid phase extraction (SPE). For the SPE (12-fold vacuum extraction box, Visiprep, 12 ports, Sigma Aldrich) the extracts were diluted to a total volume of $3 \mathrm{~mL}$ with nanopure water. The SPE cartridges (Oasis HLB $3 \mathrm{cc}, 60 \mathrm{mg}$ ) were consecutively conditioned with methanol and water $(9 \mathrm{~mL}$ each). The extracts were loaded onto the cartridges, washed with $9 \mathrm{~mL}$ nanopure water followed by $9 \mathrm{~mL} \mathrm{MeOH} / \mathrm{H}_{2} \mathrm{O}(20 / 80 \% \mathrm{v} / \mathrm{v})$ prior to elution with $9 \mathrm{~mL} \mathrm{MeOH} / \mathrm{H}_{2} \mathrm{O}(85 / 15 \% \mathrm{v} / \mathrm{v})$ at a flow

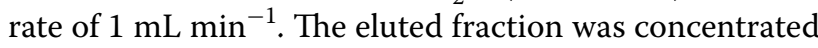
to $300 \mu \mathrm{L}$ by vacuum-assisted evaporation (Syncore $^{\circledR}$ Analyst R-12, BÜCHI Labortechnik AG, $40^{\circ} \mathrm{C}, 120 \mathrm{rpm}$, $20 \mathrm{mbar}$ ), and each volume was adjusted gravimetrically to $1.0 \mathrm{~mL}$ in nanopure water. The cyanopeptides were analyzed as described below.

\section{Simulated sunlight exposure}

Irradiation experiments were carried out in a benchtop xenon instrument that simulates sunlight (Heraeus, Suntest CPS,$+ 700 \mathrm{~W} \mathrm{~m}^{-2}$, light emission spectrum in Additional file 1: Figure S2). Cyanopeptide degradation over time was studied in lake matrix, using lake water collected from Greifensee $\left(06 / 08 / 2019,47.3663^{\circ} \mathrm{N}\right.$, $\left.8.665^{\circ} \mathrm{E}\right)$, and in buffered nanopure water at $\mathrm{pH} 7$ and 8 (5-mM phosphate buffer) and $\mathrm{pH} 9$ and $10(10-\mathrm{mM}$ carbonate buffer) with constant ionic strength $(13 \mathrm{mM}$ adjusted with sodium chloride). Aqueous cyanobacterial extracts $(200 \mu \mathrm{L})$ were added to either lake matrix or buffer solutions (total volume of $4 \mathrm{ml}$ ). Furfuryl alcohol (FFA, $40 \mu \mathrm{M}$ ) was added for quantification of singlet oxygen. The solutions were exposed to simulated sunlight for three hours in open quartz vials (Pyrex, $7.5 \mathrm{~cm}$, inner diameter $1 \mathrm{~cm}$ ), positioned at $50^{\circ}$ angle from the horizontal plane, assuring that the solutions were completely submerged in a temperature-controlled water bath $\left(20{ }^{\circ} \mathrm{C} \pm 1{ }^{\circ} \mathrm{C}\right)$. The experiments were conducted in experimental duplicate for the buffered solutions and in triplicates for the lake matrix. To monitor the light flux, the chemical actinometer system PNA-PYR was used and solutions in nanopure water $(10 \mu \mathrm{M}$ para-nitroanisole, $0.5 \mathrm{mM}$ pyridine) were irradiated along with the experiment in simulated sunlight. During the irradiation experiment, three technical replicates of $150 \mu \mathrm{L}$ were collected for time point 0 and two technical replicates were collected at different time points $(0.5,1,2,3 \mathrm{~h})$. To account for transformation independent of light, aliquots of each solution in glass vials were covered from light with tin foil and positioned next to the other exposure vials serving as dark controls. All the samples were immediately analyzed for FFA and PNA upon sampling. These samples were then frozen at $-20^{\circ} \mathrm{C}$ for further cyanopeptide analysis as detailed below.

\section{FFA and PNA analysis}

To assess the steady-state concentration of singlet oxygen $\left[{ }^{1} \mathrm{O}_{2}\right]_{\mathrm{ss}}$ and the photon fluence rate, the degradation 
of FFA and PNA was monitored, respectively. Both FFA and PNA analyses were performed by high-performance liquid chromatography (HPLC) coupled to a UV-VIS/ DAD detector (Dionex UltiMate3000 HPLC, Thermo Fischer Scientific). Chromatographic separation was carried out on an Atlantis T3 C18 column $(3 \mu \mathrm{m}, 3 \times 150 \mathrm{~mm}$, Waters) with pre-column (VanGuard ${ }^{\circledR}$ Cartridge, Waters) and inline filter $\left(\mathrm{BGB}^{\circledR}\right)$. The mobile phases consisted of (A) sodium acetate buffer ( $\mathrm{pH} 5.9 ; 15.6 \mathrm{mM} ; 10 \% \mathrm{ACN})$ and (B) acetonitrile. Isocratic elution was carried out at a flow rate of $350 \mu \mathrm{L} \mathrm{min}{ }^{-1}$ with an isocratic ratio of 90:10 (A:B) for FFA and 40:60 (A:B) for PNA. The injection volume was $20 \mu \mathrm{L}$ and detection occurred at $219 \mathrm{~nm}$ for FFA and at $316 \mathrm{~nm}$ for PNA. Measured peak areas of both FFA and PNA at each timepoint $\left(A_{t}\right)$ were normalized to their initial concentration $\left(A_{0}\right)$ and the natural logarithm of this ratio was plotted against time. The observed degradation rate constants $\left(\mathrm{k}_{\mathrm{obs}}\right.$ in $\left.\mathrm{s}^{-1}\right)$ were calculated as the slope of a linear regression. Steady-state concentrations of singlet oxygen $\left[{ }^{1} \mathrm{O}_{2}\right]_{\text {ss }}(M)$ were determined as [39]:

$$
[1 O 2]=\frac{k_{o b s}, \mathrm{FFA}}{k_{r x n}, \mathrm{FFA}},
$$

where $k_{\mathrm{obs}, \mathrm{FFA}}\left(\mathrm{s}^{-1}\right)$ is the observed degradation rate constant of FFA of each sample vial and $k_{\mathrm{rxn}, \mathrm{FFA}}\left(\mathrm{M}^{-1} \mathrm{~s}^{-1}\right)$ is the temperature-dependent second-order reaction rate constant of FFA with singlet oxygen that can be calculated according to:

$$
\ln k_{\mathrm{rxn}, \mathrm{FFA}}=\frac{(1.59 \pm 0.06) \times 10^{8}}{273.16+\mathrm{T}\left[{ }^{\circ} \mathrm{C}\right]}+(23.82 \pm 0.21)
$$

The photon fluence rate was calculated based on the $k_{\text {obs }}$ of PNA in the actinometer solutions according to established procedures (details in Additional file 1: Text S2) [40].

\section{Cyanopeptide analysis}

Cyanopeptide analysis was performed by HPLC (Dionex UltiMate3000 RS pump, Thermo Fischer Scientific) coupled to a high-resolution tandem mass spectrometer (HRMS/MS, LumosFusion Orbitrap, ThermoFisher Scientific). Chromatographic separation was carried out on a XBridgeTM C18 column $(3.5 \mu \mathrm{m}, 2.1 \times 50 \mathrm{~mm}$, Waters $)$ with pre-column (VanGuard ${ }^{\circledR}$ Cartridge, Waters) and inline filter $\left(\mathrm{BGB}^{\circledR}\right)$. The mobile phases consisted of $(\mathrm{A})$ nanopure water and (B) methanol both acidified with formic acid (0.1\%). Binary gradient elution was carried out at a flow rate of $200 \mu \mathrm{L} \mathrm{min}{ }^{-1}$ and increasing eluent B from 10 to $95 \%$ between 0 and $25 \mathrm{~min}$. The injection volume was $20 \mu \mathrm{L}$. Detection of analytes was achieved by HRMS/MS with electrospray ionization (ESI), $320^{\circ} \mathrm{C}$ capillary temperature, $4 \mathrm{kV}$ electrospray voltage and
$3500 \mathrm{~V}$ capillary voltage in positive ionization mode. Full scan accurate mass spectra were acquired from 450 to $1350 \mathrm{~m} / z$ with a nominal resolving power of 240,000 referenced at $\mathrm{m} / \mathrm{z} 250$, automated gain control (AGC) of $5 \cdot 10^{4}$, maximal injection time of $100 \mathrm{~ms}$ with $1 \mathrm{ppm}$ mass accuracy. Data-dependent high-resolution product ion spectra were obtained by stepped normalized collision energy for $\mathrm{HCD}(10,20,30,40$ and 50\%) and CID (30 and $35 \%$ ), at a resolving power of 15,000 at $400 \mathrm{~m} / z$, AGC of $1 \cdot 10^{4}$ and maximal injection time of $22 \mathrm{~ms}$. For triggering data-dependent MS/MS acquisition we included cyanopeptides from the publicly available list CyanoMetDB [18]. The suspect screening included 1219 cyanopeptides in total with 160 microcystins, 177 cyanopeptolins, 73 anabaenopeptins, 65 cyclamides, 78 microginins, 79 aeruginosins and 587 other compounds, accounting structural isomers and the mass window of $450-1350 \mathrm{~m} / z$.

\section{Cyanopeptide identification}

Data evaluation and peak area extraction were performed with Skyline 20.1 (MacCoss Lab Software). Charge states $(z=1$ and $z=2)$ and adducts $\left(\mathrm{H}^{+}, \mathrm{Na}^{+}\right)$were considered for all compounds. The identification of most cyanopeptides needed to be carried out without available reference standard materials. Thus, a comprehensive data analysis workflow established for suspect screening of micropollutant was modified and applied [41]. One major difference to micropollutant suspect screening is the fact that no spectral libraries exist for most cyanopeptide suspects. Therefore, we used in-silico fragmentation predictions to facilitate compound identification (Mass Frontier 7.0, mMass 5.5.0) and the confidence level scheme widely used for mass spectrometry by Schymanski et al. [41]. Herein, only those cyanopeptides were reported that could be identified as one of the following criteria: a cyanopeptide was identified as a tentative candidate (Level 3) based on exact mass ( $<5 \mathrm{ppm}$ mass error), accurate isotopic pattern (Skyline idotp value $>0.9$ ), and evidence from fragmentation data; a cyanopeptide was identified as probable structure (Level 2) based on complete fragmentation information confirming the connectivity of the building blocks of the peptide; and a cyanopeptide was identified as confirmed structure (Level 1) when these parameters were in agreement with available reference standards or bioreagents. The fragmentation spectra of reference standards (or bioreagents) were compared to confirmed structures in our experiments (i.e., cyanobacteria extracts) with head to tail plots using the R packages RMassBank [42] and MSMSsim [43] (Additional file 1: Figures S3-S15). Data analysis was performed in RStudio with $R$ version 3.6.1 [44]. Therefore, the HRMS 
measurement data files were converted to open.mzXML data format using the msconvert tool from ProteoWizard [45].

The peak areas of selected ion chromatograms were extracted for all cyanopeptides identified with Level 1-3 in Skyline (Version 20.1). For all cyanopeptides the $\mathrm{M}+\mathrm{H}$ ion was dominating with the exception of microcystins that contain two arginine moieties, here the $\mathrm{M}+2 \mathrm{H}$ was selected for area extraction. The identified cyanopeptides were quantified by external calibration curves of available reference standards and bioreagents in the range of 0.5$500 \mu \mathrm{g} \mathrm{L}^{-1}$. Concentrations were only reported when the peak area was above the limits of quantification (LOQs), defined as 10 times the ratio of standard deviation of the response over slope of the logarithmic calibration curve (details in Additional file 1: Table S2). For those cyanopeptides for which no reference standard or bioreagent was available, we calculated class-specific equivalents, which were calculated from external calibration curves with the structurally most similar bioreagent or standard assigned for each compound (details in Additional file 1: Table S3) according to previous work [46].

\section{Photodegradation assessment}

All first-order degradation rate constants, $k_{\mathrm{obs}}\left(\mathrm{s}^{-1}\right)$, were assessed as the slope of a linear regression of natural $\log$-transformed normalized peak area $\left(\ln \left(A_{\mathrm{t}} / A_{0}\right)\right)$ versus irradiation time. A $\mathrm{k}_{\mathrm{obs}}$ was only reported for regressions with a correlation coefficient $r^{2}>0.6$ and when the final concentration after irradiation was statistically significantly different from both, the dark control and initial concentration ( $t$-test, $p$-value $<0.05)$. If a compound degraded (i.e., significant difference between final concentration and dark control and initial concentration) but the loss did not follow pseudo-first-order kinetics (i.e., $\left.r^{2}<0.6\right)$, we report "no first-order kinetics" or "n.f.k.. If we did not observe any significant loss of concentration relative to the dark control and the initial concentration during irradiation, we report "no degradation detected" or "n.d.".

\section{Statistical analysis}

One-way analysis of variance (ANOVA) followed by Tukey pairwise comparison was employed to detect statistical significance influence of amino acid moieties and cyanopeptide class on the observed degradation rate constants by comparison of the $95 \%$ confidence intervals in RStudio (version 3.6.1).

\section{Results and discussion}

\section{Cyanopeptide profiles in four strains}

We investigated the cyanopeptide profiles of four cyanobacterial strains, $D$. flos aquae (NIVA-CYA 269/6), $M$. aeruginosa $\mathrm{PCC} 7806, M$. aeruginosa UV006, and $P$. rubescens (K-0576) by suspect screening. We identified 92 different cyanopeptides in total, 39 in D. flos aquae, 41 in $M$. aeruginosa PCC7806, 40 in M. aeruginosa UV006 and 25 in P. rubescens (details in Additional file 1: Table S4). Total cyanopeptide concentration normalized to dried biomass varied from 8 to $34 \mu \mathrm{g} \mathrm{mg}^{-1}$, with $D$. flos aquae being the strain with the highest cyanopeptide content (Fig. 1a). Data in Fig. 1b show the relative cyanopeptide profiles and all strains produced microcystins with different contributions ranging from 8 to $19 \%$. The cyanopeptide profiles of $D$. flos aquae and P. rubescens were dominated by anabaenopeptins, with contributions of 78 and $63 \%$ to the total cyanopeptide pool, respectively. The profiles of $M$. aeruginosa strains were dominated by cyanopeptolins (84\% in UV006 and 50\% in PCC7806). Overall, cyclamides were only produced by $M$. aeruginosa PCC7806

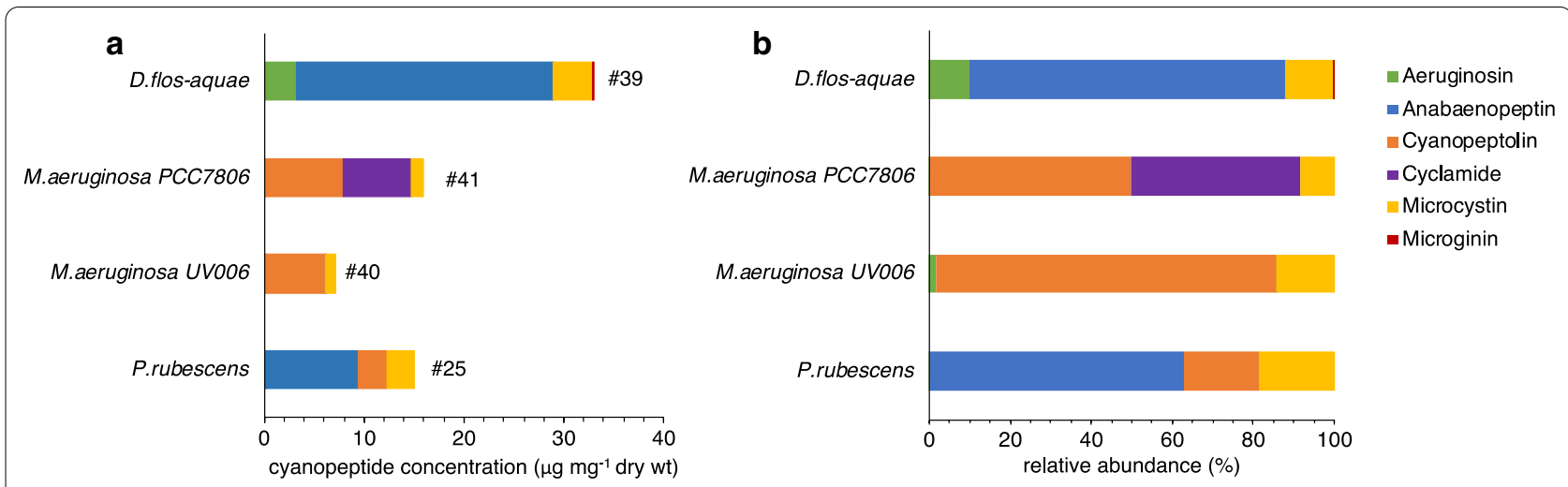

Fig. 1 Cyanopeptide profiles of four cyanobacterial strains, Dolichospermum flos aquae, Mirocystis aeruginosa PCC7806, Microcystis aeruginosa UV006 and Planktothrix rubescens, as a cyanopeptide concentration per dried biomass ( $\mu \mathrm{g} \mathrm{mg}^{-1} \mathrm{dry}$ wt) and $\mathbf{b}$ relative abundance of cyanopeptide classes including aeruginosins (green), anabaenopeptins (blue), cyanopeptolins (orange), cyclamides (purple), microcystins (yellow) and microginins (red). The number of total cyanopeptides produced by each strain is reported to the side of each bar (\#) 
with $42 \%$ relative abundance. These results support previous observations that cyanobacteria are able to produce a variety of different cyanopeptides and that the cyanopeptide profile is not only specific to one specie but also individual strains with the example of Microcystis here $[17,46-49]$.

\section{Fate of cyanopeptides in sunlit surface waters}

Cyanopeptides may undergo several transformation pathways once they are released to the surface water when cyanobacterial cells lyse. Since cyanobacterial bloom events occur predominantly during the summer period, phototransformation may be an important fate pathway. After purification of extracts from all four strains, we followed the degradation of 54 cyanopeptides during exposure to simulated sunlight in natural lake water that had a dissolved organic carbon content of $5.5 \mathrm{mg}_{\mathrm{C}} \mathrm{L}^{-1}$ and $\mathrm{pH} 9$ (Lake Greifensee water). Data in Fig. 2 show the relative abundance of the dominating cyanopeptides $(>1 \%)$ in each strain and the loss after $3 \mathrm{~h}$ of sunlight exposure (hashed portion of the bars). Cyanopeptides from D. flos aquae and P. rubescens showed the highest removal with 28 and $26 \%$, respectively. Most cyanopeptides produced by the two M. aeruginosa strains were rather persistent with only up to $3 \%$ removal in total. To the best of our knowledge, this is the first assessment of transformation that considers not only 27 microcystins variants but also 27 cyanopeptides beyond microcystins in sunlit surface water. The simulated sunlight matched the natural sunlight spectrum and the absolute intensity was approximately half of the near surface radiation in July 2013 in Zurich, Switzerland (Additional file 1: Text S2, Figure S2),

\section{a Microcystis aeruginosa PCC7806}

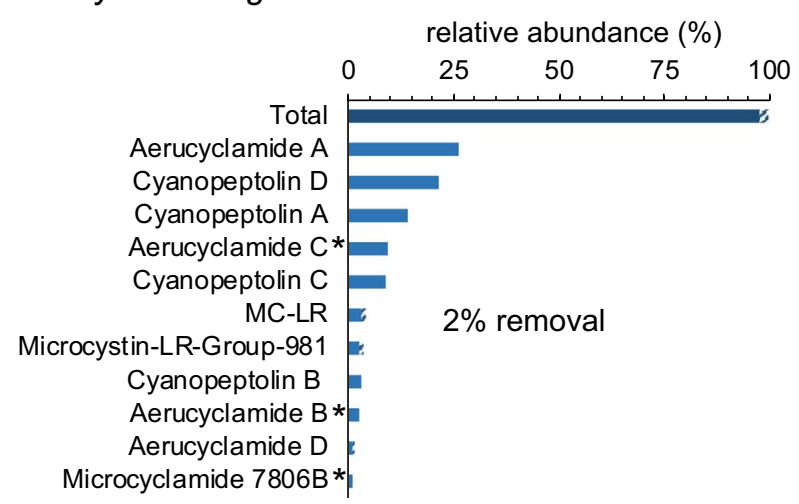

c Microcystis aeruginosa UV006

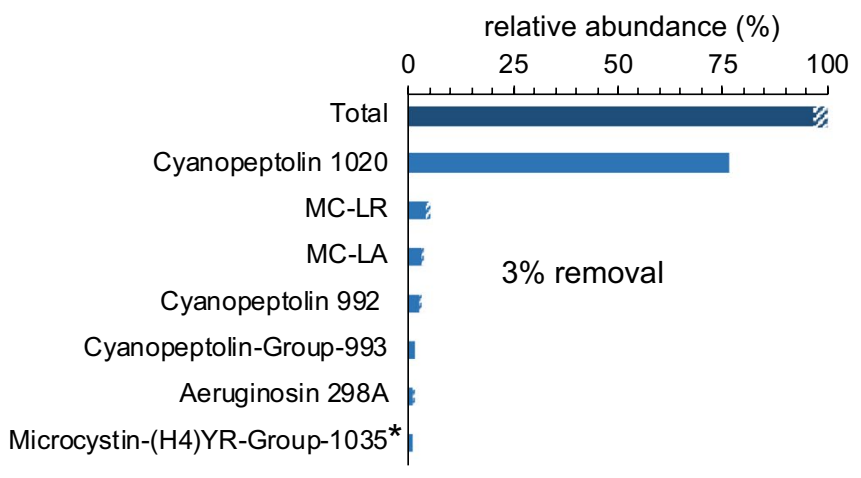

\section{b Dolichospermum flos aquae}

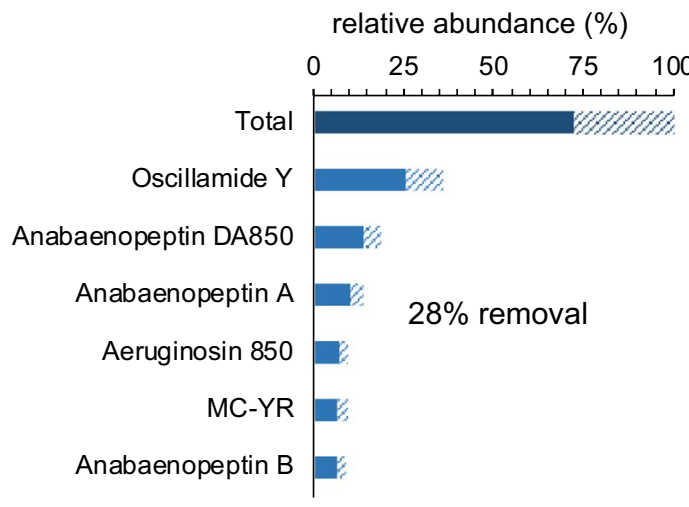

d Planktothrix rubescens

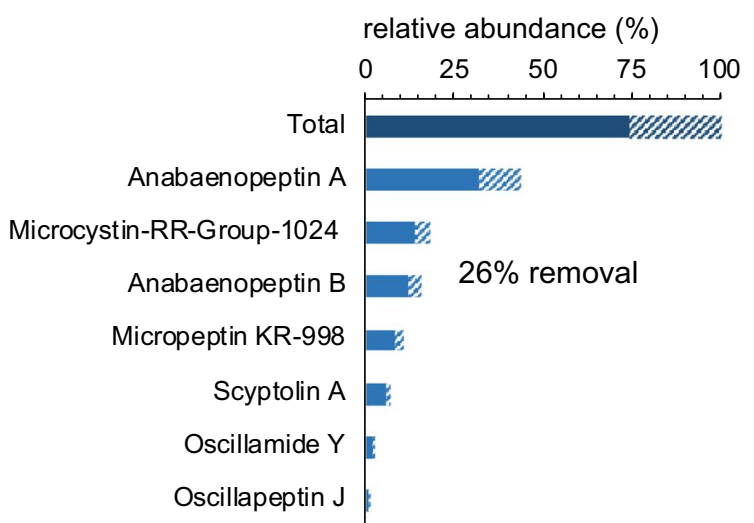

Fig. 2 Cyanopeptide profiles before and after exposure to simulated sunlight ( $\mathrm{pH}$ 9.3; DOM $5.5 \mathrm{mg}_{\mathrm{C}} \mathrm{L}^{-1}$ ) in relative abundance (\%) for a Microcystis aeruginosa PCC7806; b Dolichospermum flos aquae; c Microcystis aeruginosa UV006; d Planktothrix rubescens. The hashed portion of the bars represents the percentage removal of each cyanopeptide after $3 \mathrm{~h}$ exposure to simulated sunlight. The total percentage removal of the whole cyanopeptide pool for each specie is represented by the bar at the top of each chart (dark blue). Only cyanopeptides that contributed with more than $1 \%$ to the total cyanopeptide pool are represented here. Compound names indicated as "group" refer to structural isomers detailed in Table S5 and for the compounds marked with an asterisk (Microcystin-(H4)YR-Group-1035, Microcyclamide 7806B, Aerucyclamide B, Aerucyclamide C) the degradation could not be followed in the presented experiment 


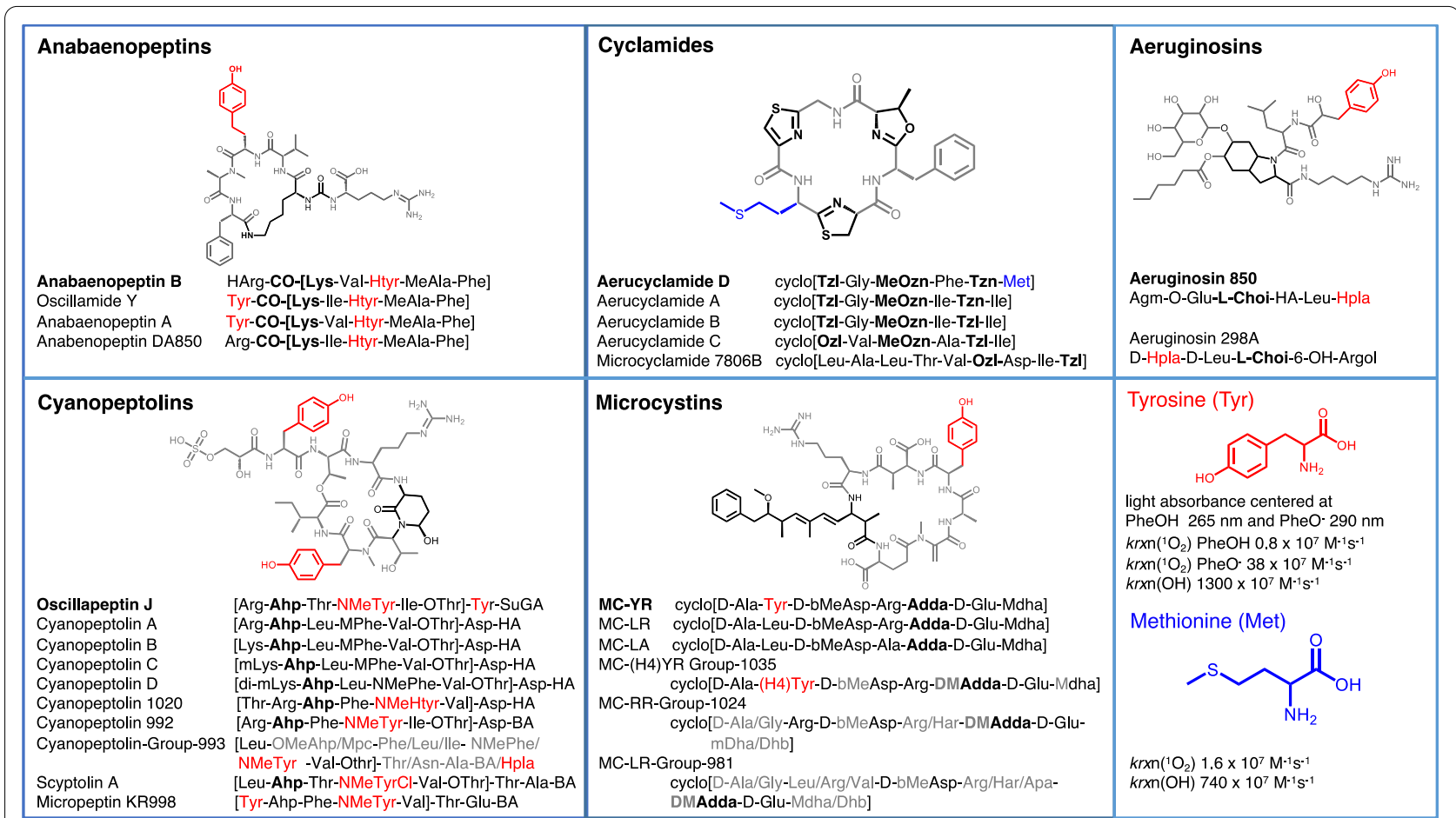

Fig. 3 Chemical structures of cyanopeptides of the classes anabaenopeptins, cyanopeptolins, cyclamides, microcystins, and aeruginosins. The characteristic core structure of each cyanopeptide class is highlighted in black, while the variable building blocks of the molecule are depicted in gray. Main peptides produced by the four cyanobacterial strains (> 1\% to total abundance) are listed with their amino acid building block strings in addition to the represented structure above. The photochemically reactive moieties of tyrosine and methionine are highlighted in red and blue, respectively. The light absorbance range and the second-order reaction rate constants with hydroxyl radical and singlet oxygen for tyrosine and methionine are listed

which allows to compare the observed rates to other light conditions of interest.

Under solar-simulated conditions, some cyanopeptides did not show measurable degradation, few degraded significantly and the majority degraded rather slowly. In the following, we inspected the degradation kinetics and amino acid composition of different cyanopeptides in more detail.

\section{Phototransformation kinetics of cyanopeptides}

We followed 54 cyanopeptides during exposure to simulated sunlight in lake water. During three hours exposure, 37 cyanopeptides degraded with half-lives of 5-14 h, and 2 cyanopeptides degraded rather fast with half-lives of $<4 \mathrm{~h}$, while 14 cyanopeptides did not follow pseudofirst-order kinetics (n.f.k.) and 1 cyanopeptide did not show any measurable degradation (n.d.); all rates are tabulated in Additional file 2: Table S6 (for data plots see Additional file 1: Figure S16). The overview in Fig. 3 shows that cyanopeptides within each class share a common core structure with variable building blocks, which can affect their susceptibility to transformation reactions.
To understand the differences in observed reactivity among cyanopeptides, we inspected these structures and the observed photochemical rates herein.

Direct phototransformation can occur when cyanopeptides absorb light in the solar spectrum $(>280 \mathrm{~nm}$ wavelength), which requires the presence of chromophoric moieties. Tryptophan is the most reactive amino acid for direct photochemical processes but does not occur in the cyanopeptides studied herein [50, 51]. In the absence of chromophores, cyanopeptides may still undergo indirect photochemical transformations. Other chromophores present in the surface water (CDOM) can absorb sunlight and react with cyanopeptides in the excited state $\left({ }^{3} \mathrm{CDOM}^{*}\right)$. In addition, ${ }^{3} \mathrm{CDOM}^{*}$ can produce reactive oxygen species, such as singlet oxygen and hydroxyl radicals. Hydroxyl radical is a non-selective oxidant that can oxidize most amino acids with up to diffusion-controlled reaction rate constants but shows relatively low steady-state concentrations in surface waters of $10^{-15}$ to $10^{-17} \mathrm{M}$ [52-54]. Singlet oxygen is a more selective oxidant known to oxidize the amino acids tyrosine, methionine, histidine, tryptophan and cysteine [54]. Together 

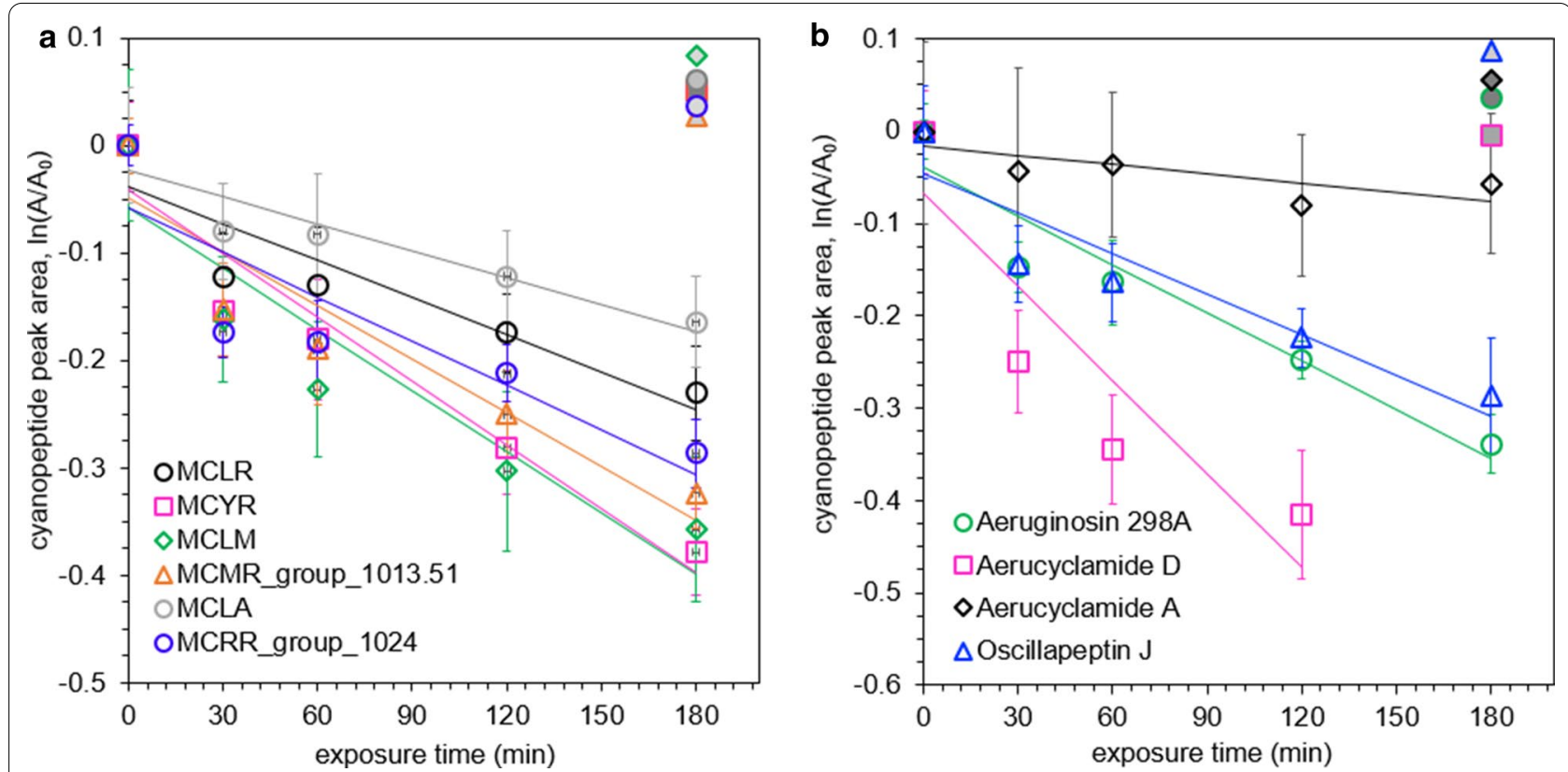

Fig. 4 Cyanopeptide degradation during exposure to simulated sunlight at $\mathrm{pH} 9$ in lake Greifensee water as the natural log-transformed peak area versus irradiation time (min) a for microcystins: MC-LA (gray), MC-LR (black), MC-RR-group-1024 (blue), MC-LM (green), MC-YR (pink) and MC-MR-group-1013.51 (orange); and b for aeruginosin 298A (green), aerucyclamide A (black), aerucyclamide D (pink), and the cyanopeptolin oscillapeptin J (blue). The filled symbols represent dark controls and the error bars represent one standard deviation

with significantly higher steady-state concentrations in sunlit surface waters ranging from $10^{-12}$ to $10^{-14} \mathrm{M}[55$, 56], singlet oxygen may be responsible for differences of observed transformation rates among cyanopeptides. The concentration of singlet oxygen in the presented experiment (lake Greifensee water, pH 9) was $1.4 \pm 0.05 \times 10^{-}$ ${ }^{13} \mathrm{M}$, which is comparable to previous observations of surface waters and supports the possibility that reactions with cyanopeptides could have occurred.

Data in Fig. 4a show the reactivity of several microcystins in irradiated lake water. MC-LA was the slowest degrading microcystin, followed by MC-LR and MC-RR-group-1024 (list of isomers in Additional file 1: Table S5) with half-lives ranging from 14 to $8 \mathrm{~h}$. These microcystins contain leucine $(\mathrm{L})$ in position 2 , arginine $(\mathrm{R})$ or alanine $(\mathrm{A})$ in position 4 and no chromophoric moieties that absorb light in the solar spectrum. Therefore, previous work observed no significant direct phototransformation for similar microcystins in sunlight $[29,30,57]$. However, in the presence of CDOM present in the lake matrix microcystins can degrade $[33,34]$. The class of microcystins is characterized by the presence of a characteristic Adda moiety, being an $(2 S, 3 S, 4 E, 6 E, 8 S, 9 S)$-3-amino-9-methoxy-2,6,8-trimethyl-10-phenyldeca-4,6-dienoic acid, or derivatives thereof. Previously, the majority of MC-LR photodegradation (approx. 60\%) was attributed to the reaction of the Adda side chain with triplet sensitizer leading to double bond isomerization and the formation of $6(\mathrm{Z})$ Adda-MC-LR [29, 33]. Since we used mass spectrometry as the detection method, we were not able to differentiate between these Adda-isomers and hence this cannot explain the observed loss herein. Singlet oxygen, in theory, can also react with the double bond of the Adda side chain, but previous work suggests that singlet oxygen contribution to phototransformation of MC-LR is only minor $[33,34]$. In addition, hydroxy radicals can react with the Adda side chain by addition to the aromatic ring and diene and dominated the photochemical reaction for MC-LR other than isomerization [58]. The second-order rate constant for the reaction of hydroxyl radical with MC-LR was determined to be $2.3 \times 10^{-}$ ${ }^{10} \mathrm{M}^{-1} \mathrm{~s}^{-1}$ [58] and 6-18\% of MC-LR total degradation in surface waters was attributed to the reaction with hydroxyl radical before [34]. Second-order reaction rate constants of individual amino acid moieties with hydroxyl radicals are available in the literature [51, 59]. The increased reactivity from MC-LA to MC-LR and MC-RR observed here during sunlight exposure in lake water, agrees with the increase in second-order reaction rate constants with hydroxyl radicals of the amino acids alanine $\left(\mathrm{A}, 0.08 \times 10^{9} \mathrm{M}^{-1} \mathrm{~s}^{-1}\right)$, leucine $(\mathrm{L}$, $\left.1.7 \times 10^{9} \mathrm{M}^{-1} \mathrm{~s}^{-1}\right)$ and arginine $\left(\mathrm{R}, 3.5 \times 10^{9} \mathrm{M}^{-1} \mathrm{~s}^{-1}\right)$. Data in Fig. 4a also show the slightly more reactive 
microcystins MC-LM, MC-MR-group-1013.51 (list of isomers in Additional file 1: Table S5), and MC-YR with half-lives of 6-7 h. These microcystin variants contain a methionine $(\mathrm{M})$ or tyrosine $(\mathrm{Y})$, which react even faster with hydroxyl radicals $\left(7.5 \times 10^{9} \mathrm{M}^{-1} \mathrm{~s}^{-1}\right.$ and $13 \times 10^{9} \mathrm{M}^{-1} \mathrm{~s}^{-1}$, respectively) [59]. Methionine and tyrosine also react with singlet oxygen with second-order reaction rate constant as freely dissolved amino acids of $1.6 \times 10^{7} \mathrm{M}^{-1} \mathrm{~s}^{-1}$ and $0.8 \times 10^{7} \mathrm{M}^{-1} \mathrm{~s}^{-1}$, respectively [60]. Here, we observed the formation of the oxidation product [D-Asp-3]MC-M(O)R, which further supports the conclusion that methionine oxidation by singlet oxygen took place (Additional file 1: Figure S17). Given the singlet oxygen concentration of $1.4 \pm 0.05 \times 10^{-13} \mathrm{M}$ during exposure and the secondorder rate constant, the expected half-lives based on reaction with singlet oxygen alone would be $83 \mathrm{~h}$ for methionine. The difference between these estimates and the observed rates is likely related to several factors including additional indirect phototransformation reactions that may occur (e.g., reaction with hydroxyl radicals or $\left.{ }^{3} \mathrm{CDOM}^{*}\right)$ [54]. The fact that most photochemical half-lives of microcystins decreased from nearly persistent conditions in buffered nanopure water at $\mathrm{pH} 9$ to short half-lives in lake water ( $\mathrm{pH} 9$, Additional file 1: Figure S18) further supports the conclusion that additional indirect phototransformation reactions contributed to cyanopeptide decay in the presence of lake matrix. Among microcystins, only MC-YR contributed significantly to the overall removal of cyanopeptides from $D$. flos aquae as other microcystins either degraded too slowly (MC-RR variants, MC-LR) or did not account for a high abundance of the cyanopeptide profile (MC-LA, MC-MR, MC-LM, Fig. 2).

Data in Fig. 4b present examples of degradation in sunlight for cyanopeptides beyond microcystins including the rather stable aerucyclamide $\mathrm{A}$ and quite reactive aerucyclamide D. Cyclamides are cyclic penta-peptides characterized by the presence of oxazoles/oxazolines and thiazoles/thiazolines moieties that are produced by M. aeruginosa PCC7806 in high abundance [37, 61]. Aerucyclamide A was stable during sunlight exposure in agreement with the lack of light absorbance in the solar spectrum and a very low reaction rate constant with singlet oxygen reported earlier $\left(1.2 \times 10^{4} \mathrm{M}^{-1} \mathrm{~s}^{-1}\right)$ [62]. Aerucyclamide D, on the other hand, degraded significantly with a half-life of $3.4 \mathrm{~h}$, which we also attribute to the presence of a methionine moiety in position 6 that differentiates it from aerucyclamide A (Fig. 3). M. aeruginosa PCC7806 presented the lowest removal of total cyanopeptides $(1.5 \%)$ and it is the only strain that contain high percentage of cyclamides in the profile. Although observed decay constants could not be obtained for
Aerucyclamide B, Aerucyclamide $\mathrm{C}$ and Microcyclamide $7806 \mathrm{~B}$, due to poor recovery during the purification process required for the experiments, we would not expect significant degradation since these peptides do not contain any photolabile building blocks.

Tyrosine-containing peptides contributed mostly to the overall high removal of cyanopeptides from $D$. flos aquae and $P$. rubescens. Data in Fig. 4 show the degradation of tyrosine-containing cyanopeptides of three different classes: MC-YR, aeruginosin 298A and the cyanopeptolin oscillapeptin J with half-lives of 6-8 h. Similar rates were observed for a total of 17 cyanopeptides that contain a tyrosine or tyrosine-like moiety, including 4 microcystins, 3 aeruginosins, 3 cyanopeptolins and 7 anabaenopeptins (Additional file 2: Table S6). Furthermore, statistical analysis showed that cyanopeptides containing the amino acids tyrosine (or its variants) and methionine are more reactive than cyanopeptides that do not contain these moieties, while there was no significant influence of cyanopeptide class on the degradation rate (Additional file 1: Figure S19-S20). Details on the $\mathrm{pH}$ dependence of tyrosine-containing cyanopeptides and their decay in sunlit surface waters is discussed in more detail below.

\section{Effect of $\mathrm{pH}$ on phototransformation of cyanopeptides}

The majority of the experiments reported in the literature that evaluate the degradation of organic molecules in surface waters are carried out at $\mathrm{pH} 7$. However, during cyanobacterial bloom events, the $\mathrm{pH}$ commonly increases in the surface waters to 8-9 [16]. Here, we also studied the effect of $\mathrm{pH}$ on the phototransformation of cyanopeptides. The cyanopeptides were exposed to buffered water and dissolved organic matter that remained from the purified cyanopeptide extracts so that direct and indirect phototransformation can occur. The singlet oxygen concentrations ranged from 0.7 to $1.3 \times 10^{-13} \mathrm{M}$ between $\mathrm{pH} 7$ and 10, and were similar to conditions in the experiment with lake water $\left(1.4 \times 10^{-13} \mathrm{M}\right)$. Overall, we observed an increase of phototransformation rates with increasing $\mathrm{pH}$ for 14 cyanopeptides and all of them contained a tyrosine or structurally related moieties (homotyrosine or Htyr; 2-hydroxy-3-(4'-hydroxy- phenyl)acetic acid or Hpla; N-methylated tyrosine or NMeTyr). Data in Fig. 5 show the observed rate constants for MC-YR, oscillapeptin J and anabaenopeptin B, three cyanopeptides that contain a tyrosine moiety. The reaction rates increased with $\mathrm{pH}$. The half-lives of these tyrosine-containing cyanopeptides decreased by one order of magnitude from nearly persistent conditions at pH 7 (half-life $>70 \mathrm{~h}$ ) to short half-lives of $<10 \mathrm{~h}$ at $\mathrm{pH} 10$. In comparison, microcystin LR did not show detectable degradation at any $\mathrm{pH}$ when no dissolved organic lake 


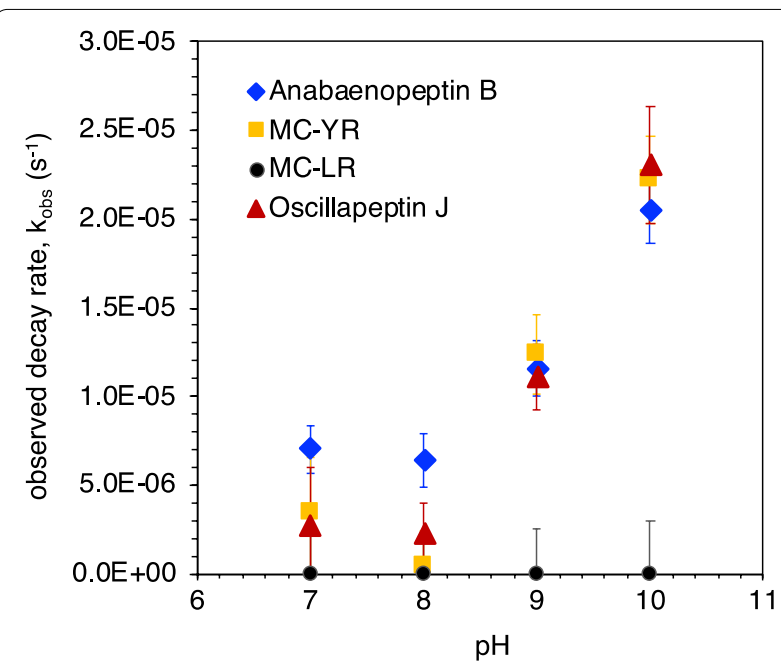

Fig. 5 Observed decay rate constant $\left(k_{\text {obs }}\right)$ versus $\mathrm{pH}$ in buffered nanopure water for anabaenopeptin B (blue diamonds), oscillapeptin $J$ (red triangles), MC-YR (yellow squares) and MC-LR (gray circles). Error bars represent one standard deviation

matrix was present (compare to data in Fig. 4a with lake matrix).

Tyrosine is known to undergo both direct and indirect phototransformation in sunlit surface waters and both processes are $\mathrm{pH}$ dependent. On one hand, the absorbance spectrum of the phenolate form of tyrosine shifts towards longer wavelength centered at $290 \mathrm{~nm}$ instead of $265 \mathrm{~nm}$ for the protonated species [63]. Consequently, tyrosine has a larger spectral overlap with sunlight at higher $\mathrm{pH}$ resulting in an increase in direct phototransformation. On the other hand, indirect photochemical reactions of tyrosine can also be influenced by $\mathrm{pH}$. The reaction with singlet oxygen is more than one order of magnitude faster at alkaline $\mathrm{pH}$ when tyrosine is deprotonated with $0.8 \times 10^{7} \mathrm{M}^{-1} \mathrm{~s}^{-1}$ at $\mathrm{pH} 7$ compared to $35 \times 10^{7} \mathrm{M}^{-1} \mathrm{~s}^{-1}$ at $\mathrm{pH} 10$ [64]. Those two factors combined explain the $\mathrm{pH}$-dependent behavior of those cyanopeptides. Further studies are necessary to clearly delineate the contribution of direct and indirect phototransformation to this $\mathrm{pH}$ effect for tyrosine-containing cyanopeptides by assessing reaction rate constants and quantum yields that can be compared to available data of freely dissolved tyrosine.

\section{Conclusions}

We assessed the concentration change of 54 cyanopeptides during $3 \mathrm{~h}$ of exposure to simulated sunlight in lake water. Of those, 37 cyanopeptides degraded with halflives of 5-14 h, and 2 cyanopeptides degraded rather fast with half-lives of $<4 \mathrm{~h}$. Overall, the total cyanopeptide concentration of $D$. flos aquae and P. rubescens presented the highest removal with 28 and 26\%, respectively. Most cyanopeptides produced by the two $M$. aeruginosa strains were rather persistent with only up to $3 \%$ removal. To the best of our knowledge, this is the first assessment of transformation kinetics in sunlit surface water that considered not only 27 microcystin variants but also 27 other cyanopeptides. Knowing the stability of cyanopeptides under environmental conditions helps to predict which cyanopeptides are more susceptible to reach drinking water treatment plants. Those abundant and persistent cyanopeptides should be prioritized for the evaluation of their abatement during water treatment and for further toxicological assessments.

We further assessed the degradation kinetics, with respect to building blocks, of the cyanopeptides known to undergo indirect photochemical reactions. The increased reactivity from MC-LA, to MC-LR, MC-RR, MC-LM, $M C-M R$ and MC-YR observed generally agrees with an increase in second-order reaction rate constants of the amino acids with hydroxyl radicals. Methionine in microcystins and aerucyclamide D resulted in shorter half-lives in sunlit lake water based on the relatively fast reactivity with singlet oxygen and hydroxyl radicals. Tyrosine and structurally related moieties are photochemically reactive building blocks commonly found in cyanopeptides across the classes of anabaenopeptins, cyanopeptolins, microcystins and aeruginosins. Analogous to the known $\mathrm{pH}$-dependent photochemistry of freely dissolved tyrosine, the photochemical half-lives of 14 tyrosine-containing cyanopeptides decreased by one order of magnitude from nearly persistent conditions at $\mathrm{pH} 7$ (half-life $>70 \mathrm{~h}$ ) to short half-lives of $<10 \mathrm{~h}$ at $\mathrm{pH} 10$. This $\mathrm{pH}$ dependence is an important finding and needs to be considered when evaluating the degradation rate of cyanotoxins and cyanopeptides in surface waters. The majority of the experiments conducted to evaluate the degradation of organic molecules in surface waters are conducted around $\mathrm{pH} 7$, which can underestimate the actual transformation rate during cyanobacterial bloom events that typically occur at higher $\mathrm{pH}$. More work is needed to differentiate the contribution of distinct photochemical reaction pathways to the $\mathrm{pH}$ effect.

\section{Supplementary Information}

The online version contains supplementary material available at https://doi. org/10.1186/s12302-021-00465-3.

Additional file1: Figure S1. Absorbance spectra for extracts of cyanobacteria pooled from Dolichospermum flos aquae, Microcystis aeruginosa PCC7806, Microcystis aeruginosa UV006 and Planktothrix rubescens before (dark green upper line) and after (light green lower line) purification by liquid-liquid extraction. The absorbance spectra were corrected by extract volume analysed. Figure S2. Light spectrum comparison of the solar simulator Heraeus Suntest CPS+(black) versus natural sunlight measured in Zurich on July 2013 (blue) showing the 
absolute light flux (A) and relative light intensities (B). Figure S3. Comparison of relative intensity over $\mathrm{m} / \mathrm{z}$ range for mass spectrometry fragmentation spectra between Aerucyclamide A bioreagent (top, orange) and cyanobacterial extract spiked in lake matrix (bottom, blue) as head to tail plots. The $\mathrm{m} / \mathrm{z}$ value, the retention time (RT in $\mathrm{min}$ ) and the $\mathrm{HCD}$ collision energy are noted in the title line. Figure S4. Comparison of relative intensity over $\mathrm{m} / \mathrm{z}$ range for mass spectrometry fragmentation spectra between Anabaenopeptin A bioreagent (top, orange) and cyanobacterial extract spiked in lake matrix (bottom, blue) as head to tail plots. The $\mathrm{m} / \mathrm{z}$ value, the retention time (RT in $\mathrm{min}$ ) and the HCD collision energy are noted in the title line. Figure $\mathbf{S 5}$. Comparison of relative intensity over $\mathrm{m} / \mathrm{z}$ range for mass spectrometry fragmentation spectra between Anabaenopeptin B bioreagent (top, orange) and cyanobacterial extract spiked in lake matrix (bottom, blue) as head to tail plots. The $\mathrm{m} / \mathrm{z}$ value, the retention time (RT in min) and the HCD collision energy are noted in the title line. Figure $\mathbf{S 6}$. Comparison of relative intensity over $\mathrm{m} / \mathrm{z}$ range for mass spectrometry fragmentation spectra between Cyanopeptolin A bioreagent (top, orange) and cyanobacterial extract spiked in lake matrix (bottom, blue) as head to tail plots. The $\mathrm{m} / \mathrm{z}$ value, the retention time (RT in min) and the HCD collision energy are noted in the title line. Figure $\mathbf{S 7}$. Comparison of relative intensity over $\mathrm{m} / \mathrm{z}$ range for mass spectrometry fragmentation spectra between Cyanopeptolin D bioreagent (top, orange) and cyanobacterial extract spiked in lake matrix (bottom, blue) as head to tail plots. The $\mathrm{m} / \mathrm{z}$ value, the retention time (RT in $\mathrm{min}$ ) and the HCD collision energy are noted in the title line. Figure $\mathbf{8 8 .}$ Comparison of relative intensity over $\mathrm{m} / \mathrm{z}$ range for mass spectrometry fragmentation spectra between Microcystin LA standard (top, orange) and cyanobacterial extract spiked in lake matrix (bottom, blue) as head to tail plots. The $\mathrm{m} / \mathrm{z}$ value, the retention time (RT in $\mathrm{min}$ ) and the HCD collision energy are noted in the title line. Figure $\mathbf{5 9}$. Comparison of relative intensity over $\mathrm{m} / \mathrm{z}$ range for mass spectrometry fragmentation spectra between Microcystin LF standard (top, orange) and cyanobacterial extract spiked in lake matrix (bottom, blue) as head to tail plots. The $\mathrm{m} / \mathrm{z}$ value the retention time (RT in $\mathrm{min}$ ) and the HCD collision energy are noted in the title line. Figure $\mathbf{S 1 0}$. Comparison of relative intensity over $\mathrm{m} / \mathrm{z}$ range for mass spectrometry fragmentation spectra between Microcystin LR standard (top, orange) and cyanobacterial extract spiked in lake matrix (bottom, blue) as head to tail plots. The $\mathrm{m} / \mathrm{z}$ value, the retention time (RT in $\mathrm{min}$ ) and the HCD collision energy are noted in the title line. Figure S11. Comparison of relative intensity over $\mathrm{m} / \mathrm{z}$ range for mass spectrometry fragmentation spectra between Microcystin LW standard (top, orange) and cyanobacterial extract spiked in lake matrix (bottom, blue) as head to tail plots. The $\mathrm{m} / \mathrm{z}$ value, the retention time (RT in $\mathrm{min}$ ) and the HCD collision energy are noted in the title line. Figure S12. Comparison of relative intensity over $\mathrm{m} / \mathrm{z}$ range for mass spectrometry fragmentation spectra between Microcystin LY standard (top, orange) and cyanobacterial extract spiked in lake matrix (bottom, blue) as head to tail plots. The $\mathrm{m} / \mathrm{z}$ value, the retention time (RT in min) and the HCD collision energy are noted in the title line. Figure $\mathbf{S 1 3}$. Comparison of relative intensity over $\mathrm{m} / \mathrm{z}$ range for mass spectrometry fragmentation spectra between Microcystin YR standard (top, orange) and cyanobacterial extract spiked in lake matrix (bottom, blue) as head to tail plots. The $\mathrm{m} / \mathrm{z}$ value, the retention time (RT in $\mathrm{min}$ ) and the HCD collision energy are noted in the title line. Figure S14. Comparison of relative intensity over $\mathrm{m} / \mathrm{z}$ range for mass spectrometry fragmentation spectra between Oscillamide $Y$ bioreagent (top, orange) and cyanobacterial extract spiked in lake matrix (bottom, blue) as head to tail plots. The $\mathrm{m} / \mathrm{z}$ value, the retention time (RT in $\mathrm{min}$ ) and the HCD collision energy are noted in the title line. Figure $\mathrm{S} 15$. Comparison of relative intensity over $\mathrm{m} / \mathrm{z}$ range for mass spectrometry fragmentation spectra between [D-Asp3,E-Dhb7]-MC-RR bioreagent (top, orange) and cyanobacterial extract spiked in lake matrix (bottom, blue) as head to tail plots. The $\mathrm{m} / \mathrm{z}$ value, the retention time (RT in min) and the CID collision energy are noted in the title line. The head to tail plot suggests that the compound present in the cyanobacterial extract is a different structural isomer from the Microcystin-Group-1024. Figure S16. Cyanopeptide degradation during exposure to simulated sunlight at $\mathrm{pH} 9$ in lake Greifensee water as the natural log-transformed peak areas versus irradiation time (min) for seven anabaenopeptins, two aeruginosins, three cyanopeptolins and 18 microcystins. The filled symbols represent dark controls, the error bars represent one standard deviation, the dark red line represent the linear model and the dashed red lines represent the 95\% confidence interval. Figure S17. Change of concentration of [D-Asp-3] MC-MR and its oxidated variant [DAsp- 3]MC-M(O)R, which was present in the starting material but increased during photochemical exposure indicating that it was formed, potentially from oxidation of [D-Asp-3] MC-MR. Figure S18. Comparison of cyanopeptide degradation during exposure to simulated sunlight at pH 9 in lake Greifensee water (full line) and in buffered water (dashed line) as the natural log-transformed peak area versus irradiation time (min) for microcystins: MC-LR (A), MC-LA (B), MC-RR-variant group 1024 (C), MC-LM (D), MC-MR (E) and MC-YR (F); The filled symbols represents dark controls and the error bars represents one standard deviation. The first-order degradation rate constants, kobs $(s-1)$ for lake matrix and buffered water and the $p$-value of the t-test of the slope between conditions for each cyanopeptide are listed. Figure S19. Observed decay rate (kobs, s-1) for the 37 cyanopeptides that presented first-order decay relative to the presence of selected amino acid moieties: no photolabile moiety ("none", coral), methionine (yellow), oxidized tryptophan (green), tyrosine variant (blue), and phenylalanine (pink). P-values of Tukey pairwise ANOVA from comparison to cyanopeptides with no photolabile amino acids are listed as ${ }^{* *} p$-value $<0.001$ and ${ }^{*} p$-value $<0.05$. Figure $\mathbf{S 2 0}$. Observed decay rate (kobs, s-1) for the 37 cyanopeptides that presented first-order decay relative to the cyanopeptide class of microcystin (coral), cyclamide (yellow), aeruginosin (green), anabaenopeptin (blue), and cyanopeptolin (pink). One-way ANOVA did not indicate any significance difference between classes ( $p$-value $=0.501$ ) Figure S21. MS/MS annotation at HCD30 for Anabaenopeptin F. Figure S22. MS/MS annotation at HCD20 for Microcystin-LM. Text S1. Additional Materials. Text S2. Photon fluence rate. Table S1. Composition of modified WC growth medium (Guillard 1972). Table S2. Standard analytical information including: limit of detection (LOD) and limit of quantification (LOQ) for the reference standards and bioreagents in lake matrix experiment and buffered nanopure water for $\mathrm{pH}$ range experiments. Table S3. List of compounds and their respective bioreagent or reference standard used for quantification as class equivalents by external calibration curve. Table S4. List of all tentatively identified cyanopeptides in cell extracts of Dolichopermum flos aquae, Microcystis aeruginosa PCC7806, Microcystis aeruginosa UV006 and Planktothrix rubescens. Only the peptides that could be classified as tentative candidate (level 3), probable structure (level 2) or confirmed structure (level 1) are reported. Cyanopeptide references can be found at CyanometDB (Jones et al.). Only compounds above LOQ are reported. Table S5. Isobaric compound group name (cyanopeptide class-group-MW) and individual compounds within each group with the same molecular formula. Only compounds above LOQ are reported.

Additional file 2: Table S6. Observed degradation rates (kobs) for 54 cyanopeptides in lake matrix and buffered solutions at pH 7-10 are provided as a separate datasheet supplied as supporting information of this manuscript.

\section{Acknowledgements}

We thank Martin Jones for improving the cyanopeptide database and valuable discussions, Marta Reyes and Francesco Pomati for culturing support, Karl Gademann for providing aerucyclamide A, and Jakob Pernthaler for inoculum of M. aeruginosa UV006.

\section{Author's contributions}

RN: conceptualization, investigation, experimental analysis, data evaluation and visualization, writing (original draft) and editing. SM: experimental analysis, data evaluation. EJ: supervision, conceptualization, data evaluation, reviewing and editing writing. All authors read and approved the final manuscript.

\section{Funding}

This study has received funding from the European Union's Horizon 2020 research and innovation program under the Marie Sklodowska-Curie Grant Agreement No. 722493.

\section{Availability of data and materials}

Supplementary information available and an additional datafile containing Additional file 2: Table S6. The datasets obtained and analysed in the current study are available from the corresponding author on reasonable request. 
Ethics approval and consent to participate

Not applicable.

\section{Consent for publication}

Not applicable.

\section{Competing interest}

The authors declare that they have no competing interest.

\begin{abstract}
Author details
${ }^{1}$ Department of Environmental Chemistry, Swiss Federal Institute of Aquatic Science and Technology (Eawag), 8600 Dübendorf, Switzerland. ${ }^{2}$ School of Architecture, Civil and Environmental Engineering (ENAC), Environmental Engineering Institute (IIE), Laboratory for Water Quality and Treatment (LTQE), École Polytechnique Fédérale de Lausanne (EPFL), 1015 Lausanne, Switzerland.
\end{abstract}

\section{Received: 18 November 2020 Accepted: 5 February 2021}

Published online: 01 March 2021

\section{References}

1. Huisman J et al (2018) Cyanobacterial blooms. Nat Rev Microbiol 16(8):471-483

2. Kosten $\mathrm{S}$ et al (2012) Warmer climates boost cyanobacterial dominance in shallow lakes. Glob Change Biol 18(1):118-126

3. Beaulieu M, Pick F, Gregory-Eaves I (2013) Nutrients and water temperature are significant predictors of cyanobacterial biomass in a 1147 lakes data set. Limnol Oceanogr 58(5):1736-1746

4. Cavicchioli R et al (2019) Scientists' warning to humanity: microorganisms and climate change. Nat Rev Microbiol 17(9):569-586

5. Paerl HW, Huisman J (2008) Climate_blooms like it hot. Science 320(5872):57-58

6. Pouria S et al (1998) Fatal microcystin intoxication in haemodialysis unit in Caruaru Brazil. Lancet 352(9121):21-26

7. Merel $\mathrm{S}$ et al (2013) State of knowledge and concerns on cyanobacterial blooms and cyanotoxins. Environ Int 59:303-327

8. Janssen EML (2019) Cyanobacterial peptides beyond microcystins - a review on co-occurrence, toxicity, and challenges for risk assessment. Water Res 151:488-499

9. Agha R, Quesada A (2014) Oligopeptides as biomarkers of cyanobacterial subpopulations toward an understanding of their biological role. Toxins 6(6):1929-1950

10. Carmichael WW (2001) Health effects of toxin-producing cyanobacteria: "The CyanoHABs." Hum Ecol Risk Assess 7(5):1393-1407

11. Matsunaga $\mathrm{H}$ et al (1999) Possible cause of unnatural mass death of wild birds in a pond in Nishinomiya Japan Sudden appearance of toxic cyanobacteria. Nat Toxins 7(2):81

12. Chen J et al (2009) First identification of the hepatotoxic microcystins in the serum of a chronically exposed human population together with indication of hepatocellular damage. Toxicol Sci 108(1):81-89

13. Bogialli $S$ et al (2017) Liquid chromatography-high resolution mass spectrometric methods for the surveillance monitoring of cyanotoxins in freshwaters. Talanta 170:322-330

14. Flores C, Caixach J (2015) An integrated strategy for rapid and accurate determination of free and cell-bound microcystins and related peptides in natural blooms by liquid chromatography-electrospray-high resolution mass spectrometry and matrix-assisted laser desorption/ionization time-of-flight/time-of-flight mass spectrometry using both positive and negative ionization modes. J Chromatogr A 1407:76-89

15. Saker ML et al (2005) Variation between strains of the cyanobacterium Microcystis aeruginosa isolated from a Portuguese river. J Appl Microbiol 99(4):749-757

16. Beversdorf $L$ et al (2017) Variable cyanobacterial toxin and metabolite profiles across six eutrophic lakes of differing physiochemical characteristics. Toxins (Basel) 9(2):62

17. Welker M et al (2004) Diversity and distribution of Microcystis (Cyanobacteria) oligopeptide chemotypes from natural communities studied by single-colony mass spectrometry. Microbiology-Sgm 150:1785-1796

18. Jones MR et al (2020) Comprehensive database of secondary metabolites from cyanobacteria. https://doi.org/10.1101/2020.04.16.038703
19. Chorus I et al (2006) Toxic and bioactive peptides in cyanobacteriaPEPCY report. https://www.uibk.ac.at/limno/files/pdf/final-report-pepcy .pdf.

20. Roy-Lachapelle A et al (2019) A data-independent methodology for the structural characterization of microcystins and anabaenopeptins leading to the identification of four new congeners. Toxins 11(11):619

21. Beversdorf $L J$ et al (2018) Analysis of cyanobacterial matebolites in surface water and raw drinking waters reveals more than microcystin. Water Res 140:280-290

22. Edwards C et al (2008) Biodegradation of microcystins and nodularin in freshwaters. Chemosphere 73(8):1315-1321

23. Mazur H, Pliñski M (2001) Stability of cyanotoxins, microcystin-LR, microcystin-RR and nodularin in seawater and BG-11 medium of different salinity. Oceanologia 43(3):329-339

24. Welker M, Steinberg C, Jones G (2001) Release and persistence of microcystins in natural waters. Microbial degradation of microcystins. In: Chorus I (ed) Cyanotoxins: occurrence, causes, consequences, 1st edn. Springer, Berlin, Heidelberg, pp 88-93. https://doi.org/10.1007/978-3642-59514-1

25. Cousins IT et al (1996) Biodegradation of microcystin-LR by indigenous mixed bacterial populations. Water Res 30(2):481-485

26. Kohler E et al (2014) Biodegradation of microcystins during gravity-driven membrane (GDM) ultrafiltration. PLoS ONE. https://doi.org/10.1371/journ al.pone.0111794

27. Lawton LA et al (2011) Novel bacterial strains for the removal of microcys tins from drinking water. Water Sci Technol 63(6):1137-1142

28. Wormer L et al (2010) Natural photodegradation of the cyanobacterial toxins microcystin and cylindrospermopsin. Environ Sci Technol 44(8):3002-3007

29. Tsuji K et al (1995) Stability of microcystins from cyanobacteria. 2.Effect of UV light on decomposition and isomerization. Toxicon 33(12):1619-1631

30. Welker M, Steinberg C (2000) Rates of humic substance photosensitized degradation of microcystin-LR in natural waters. Environ Sci Technol 34(16):3415-3419

31. Welker M, Steinberg C, Jones G (2001) Release and persistence of microcystins in natural waters. Photosensitized degradation of microcystins. In: Chorus I (ed) Cyanotoxins: occurrence, causes, consequences, 1st edn. Springer, Berlin, Heidelberg, pp 93-98. https://doi.org/10.1007/978-3642-59514-1

32. McNeill K, Canonica S (2016) Triplet state dissolved organic matter in aquatic photochemistry: reaction mechanisms, substrate scope, and photophysical properties. Environ Sci Process Impacts 18(11):1381-1399

33. Song WH, Bardowell S, O'Shea KE (2007) Mechanistic study and the influence of oxygen on the photosensitized transformations of microcystins (cyanotoxins). Environ Sci Technol 41(15):5336-5341

34. Yan SW, Zhang D, Song WH (2014) Mechanistic considerations of photosensitized transformation of microcystin-LR (cyanobacterial toxin) in aqueous environments. Environ Pollut 193:111-118

35. Sun QY et al (2018) Ultraviolet photosensitized transformation mechanism of microcystin-LR by natural organic matter in raw water. Chemosphere 209:96-103

36. Bouaicha N et al (2019) Structural diversity, characterization and toxicology of microcystins. Toxins 11(12):714

37. Portmann C et al (2008) Aerucyclamides A and B: Isolation and synthesis of toxic ribosomal heterocyclic peptides from the cyanobacterium Microcystis aeruginosa PCC 7806. J Nat Prod 71(7):1193-1196

38. Guillard RR, Lorenzen CJ (1972) Yellow-green algae with chlorophyllide C. J Phycol 8(1):10-000

39. Appiani E et al (2017) Aqueous singlet oxygen reaction kinetics of furfuryl alcohol: effect of temperature, $\mathrm{pH}$, and salt content. Environ Sci Process Impacts 19(4):507-516

40. Dulin D, Mill T (1982) Development and evaluation of sunlight actinometers. Environ Sci Technol 16(11):815-820

41. Schymanski EL et al (2014) Identifying small molecules via high resolution mass spectrometry: communicating confidence. Environ Sci Technol 48(4):2097-2098

42. Stravs MA et al (2013) Automatic recalibration and processing of tandem mass spectra using formula annotation. J Mass Spectrom 48(1):89-99

43. Schollée JE (2017) MSMSsim: functions for processing HRMS2 spectra from output from RMassBank, mainly for calculating spectral similarity. https://github.com/dutchjes/MSMSsim 2017. 
44. RStudio T (2019) RStudio.integarted development for R. RStudio, Inc., Boston, MA URL http://www.rstudio.com/.

45. Chambers MC et al (2012) A cross-platform toolkit for mass spectrometry and proteomics. Nat Biotechnol 30(10):918-920

46. Natumi R, Janssen EML (2020) Cyanopeptide co-production dynamics beyond mirocystins and effects of growth stages and nutrient availability. Environ Sci Technol 54(10):6063-6072

47. Welker M, Christiansen G, von Dohren H (2004) Diversity of coexisting Planktothrix (Cyanobacteria) chemotypes deduced by mass spectral analysis of microystins and other oligopeptides. Arch Microbiol 182(4):288-298

48. Tonk $L$ et al (2009) Production of cyanopeptolins, anabaenopeptins, and microcystins by the harmful cyanobacteria Anabaena 90 and Microcystis PCC 7806. Harmful Algae 8(2):219-224

49. Carneiro RL et al (2012) Co-occurrence of microcystin and microginin congeners in Brazilian strains of Microcystis sp. FEMS Microbiol Ecol 82(3):692-702

50. Janssen EML, Erickson PR, McNeill K (2014) Dual roles of dissolved organic matter as sensitizer and quencher in the photooxidation of tryptophan. Environ Sci Technol 48(9):4916-4924

51. Lundeen RA et al (2014) Environmental photochemistry of amino acids peptides and proteins. Chimia (Aarau) 68(11):812-817

52. Page SE, Arnold WA, McNeill K (2011) Assessing the contribution of free hydroxyl radical in organic matter-sensitized photohydroxylation reactions. Environ Sci Technol 45(7):2818-2825

53. Haag WR, Hoigne J (1985) Photo-sensitized oxidation in natural-water via $\mathrm{OH}$ radicals. Chemosphere 14(11-12):1659-1671

54. Boreen AL et al (2008) Indirect photodegradation of dissolved free amino acids: the contribution of singlet oxygen and the differential reactivity of DOM from various sources. Environ Sci Technol 42(15):5492-5498

55. Wolff CJM, Halmans MTH, Vanderheijde HB (1981) The formation of singlet oxygen in surface waters. Chemosphere 10(1):59-62
56. Zepp RG et al (1977) Singlet oxygen in natural-waters. Nature 267(5610):421-423

57. Leon C et al (2019) Study of cyanotoxin degradation and evaluation of their transformation products in surface waters by LC-QTOF MS. Chemosphere 229:538-548

58. Song WH et al (2009) Radiolysis studies on the destruction of microcystin-LR in aqueous solution by hydroxyl radicals. Environ Sci Technol 43(5):1487-1492

59. Buxton GV et al (1988) Critical-review of rate constants for reactions of hydrated electrons, hydrogen-atoms and hydroxyl radicals (.Oh/.O-) in aqueous-solution. J Phys Chem Ref Data 17(2):513-886

60. Matheson IBC, Lee J (1979) Chemical-reaction rates of amino-acids with singlet oxygen. Photochem Photobiol 29(5):879-881

61. Portmann C et al (2008) Isolation of aerucyclamides C and D and structure revision of microcyclamide 7806A: Heterocyclic ribosomal peptides from Microcystis aeruginosa PCC 7806 and their antiparasite evaluation. J Nat Prod 71(11):1891-1896

62. Manfrin A et al (2019) Singlet oxygen photooxidation of peptidic oxazoles and thiazoles. J Org Chem 84(5):2439-2447

63. Antosiewicz JM, Shugar D (2016) UV-vis spectroscopy of tyrosine sidegroups in studies of protein structure part 1: basic principles and properties of tyrosine chromophore. Biophys Rev 8(2):151-161

64. Bertolotti SG, Garcia NA, Arguello GA (1991) Effect of the peptide-bond on the singlet-molecular-oxygen-mediated sensitized photooxidation of tyrosine and tryptophan dipeptides - a kinetic-study. J Photochem Photobiol B Biol 10(1-2):57-70

\section{Publisher's Note}

Springer Nature remains neutral with regard to jurisdictional claims in published maps and institutional affiliations.

\section{Submit your manuscript to a SpringerOpen ${ }^{\circ}$ journal and benefit from:}

- Convenient online submission

- Rigorous peer review

- Open access: articles freely available online

- High visibility within the field

- Retaining the copyright to your article

Submit your next manuscript at $\boldsymbol{\nabla}$ springeropen.com 